\title{
More reasons to dread rain on vacation? Dengue fever in 42 German and United Kingdom Madeira tourists during autumn 2012
}

C Frank (FrankC@rki.de) ${ }^{1}$, M Höhle ${ }^{1}$, K Stark ${ }^{1}$, J Lawrence ${ }^{2}$

1. Robert Koch Institute, Dept. for Infectious Disease Epidemiology, Berlin, Germany

2. Travel and Migrant Health Section, Centre for Infectious Disease Surveillance and Control, Public Health England, London, United Kingdom

Citation style for this article:

Frank C, Höhle M, Stark K, Lawrence J. More reasons to dread rain on vacation? Dengue fever in 42 German and United Kingdom Madeira tourists during autumn 2012. Euro Surveill. 2013;18(14):pii=20446. Available online: http://www.eurosurveillance.org/ViewArticle.aspx?Articleld=20446

In October and November 2012 residents and tourists in the Autonomous Region of Madeira, Portugal, were affected by dengue fever. The outbreak waned during the unusually dry winter. Using a Monte Carlo test we investigated the hypothesis that rainy weather conveyed increased risk of dengue virus infection among tourists. Results confirmed the hypothesis. As it is unclear whether the outbreak is over, upkeep and emphasis on mosquito avoidance on rainy days may help residents and tourists reduce infection risk.

\section{Background}

Public health authorities in the Autonomous Region of Madeira (RAM), Portugal have been monitoring an outbreak of dengue fever beginning October 2012 [1]. RAM is an archipelago in the Atlantic, politically part of Portugal but closer to Africa and on the same latitude as the African north coast. At $32^{\circ}$ northern latitude the islands have a maritime and subtropical climate. Rains fall predominantly in the months of October through March [2]. As of 3 February 2013, over 2,000 cases among residents of Madeira had been reported, most between October and November 2012 [3]. In addition, 78 cases from 13 European countries (including travellers from mainland Portugal) have been reported by the European Centre for Disease Prevention and Control (ECDC) in tourists to Madeira, including 19 from Germany and 23 from the United Kingdom (UK) [4]. The number of cases decreased in December 2012 [2] although a small number of cases in residents and tourists have continued to be reported throughout January and February 2013 [5-7].

A non-statistical comparison of German case data with rainfall information from an internet data source [8] led to the hypothesis, that visiting Madeira in autumn 2012 during rainy days conferred a higher dengue virus infection risk than visiting during drier periods. To test this hypothesis, a Monte Carlo simulation with information from 19 German and 23 UK cases together with Madeira weather data, was used. The results may help to interpret a relative dearth of new cases since December and offer risk reduction guidance for residents in and tourists visiting Madeira.

\section{Methods}

The German National Weather Service provided validated information on rainfall at Funchal, Madeira, weather station between 1 July 2012 and 20 January 2013 (6 am $24 \mathrm{~h}$ reading projected on the preceding date) [9]. Laboratory-confirmed clinical dengue cases with known travel history to Madeira, as well as dates of travel to Madeira, sex, age and symptom onset dates, were extracted from the German database on notifiable infectious diseases [10] and the UK national dengue database [11]. Starting with the first reported cases which occurred in September 2012 this yielded a total of 42 cases. Based on a potential dengue fever incubation period of three to 14 days [12], likely risk periods on the island were calculated: date of arrival, or date of onset minus 14 days (whichever came later), to three days before symptom onset or date of departure (whichever came earlier).

A Monte Carlo test was performed as follows: in the absence of actual control travellers, the travels to Madeira of 42 German and UK hypothetical travellers were simulated 9,999 times. Data on German [13] and UK [14] traveller numbers per month were used as weights to account for any fluctuations in traveller numbers. For each simulation, 42 start dates (i.e. arrival dates to Madeira) between 15 September and 21 December 2012 were drawn at random from all available dates, each day's probability to be drawn proportional to the country-respective traveller numbers. In the two separate country groups, the cases' risk periods were randomly allotted with replacement to these starting dates, yielding 42 risk periods per set. These 9,999 control sets and the actual 42 cases were compared on the following criteria: Whether they had 
Travel periods to Madeira and symptom onset dates of German and United Kingdom laboratory-confirmed dengue cases, relative to daily precipitation and maximum temperature in Funchal, Madeira, 1 August 2012-19 January 2013 (n=42 cases)

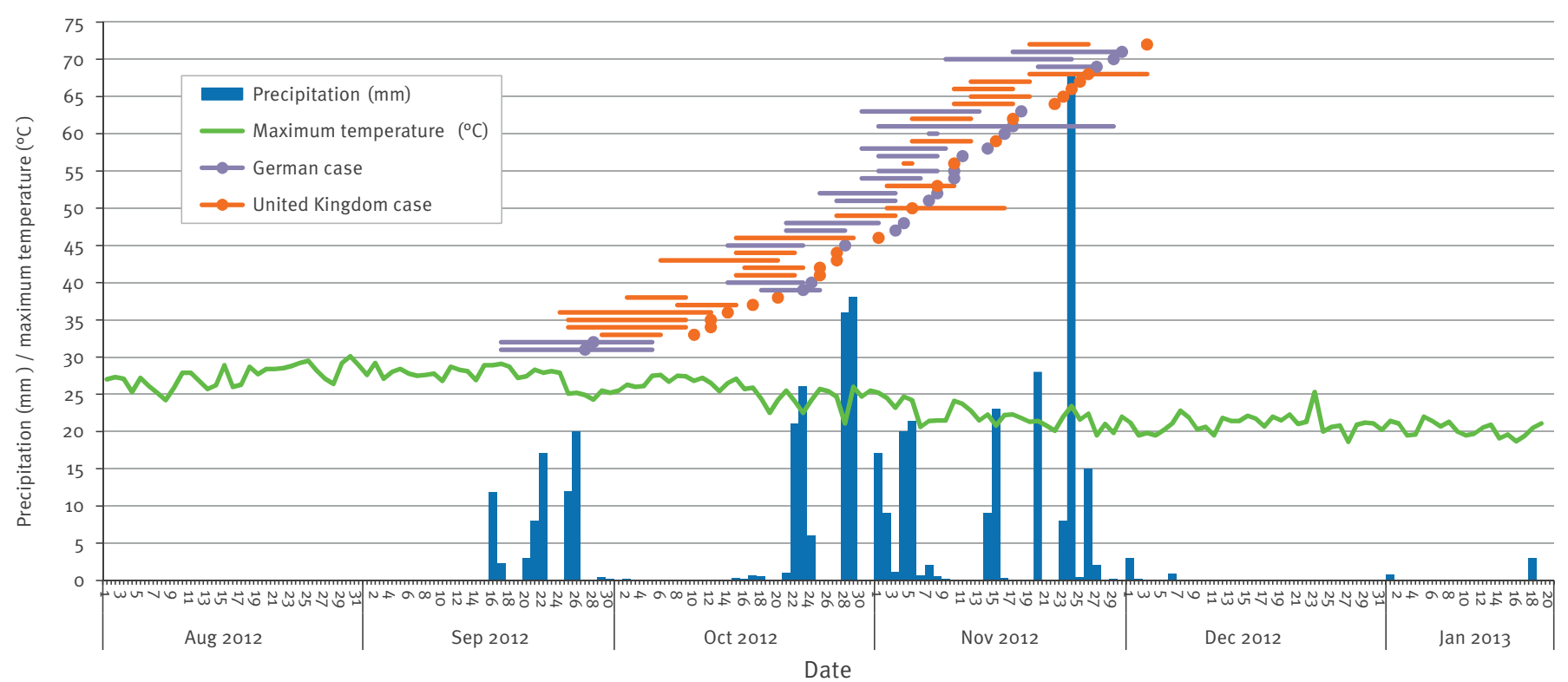

Travel periods of the cases to Madeira are indicated by horizontal bars. Dots represent cases at time of symptom onset.

experienced any rain at all (>o $\mathrm{mm}$ ), what proportion of days during their risk period had been rainy, and the mean daily $\mathrm{mm}$ of rain during their risk period. A onesided Monte Carlo $p$-value was determined as the number of realisations among the 10,000, having a value equal to or more extreme than the actual observed value in the set of cases.

\section{Results}

Between September 2012 and March 2013, 42 cases of dengue fever were reported in Germany and the UK, including 19 from Germany and 23 from the UK. For all cases, complete data were available. Symptom onset dates ranged from 27 September to 3 December 2012. Sex distribution was even, median age was 57 (range: 20-73) years. Median duration of travel was eight days (range: 1-29).

Figure 1 shows cases' travel periods and onset dates relative to daily rainfall totals and maximum daily temperature between 1 August 2012 and 19 January 2013.

In the statistical comparison between the 42 cases and the simulated travellers (Figure 2), 40 of 42 cases (95.2\%) experienced at least one day of rain during their risk period. Altogether, in the 10,000 realisations, a set with $92.5 \%$ or more* of the simulated travellers experiencing any rain during their risk period was very unlikely $(808 / 10,000, p=0.0808)$. For the only two cases without rain in their risk period it rained on the day of their departure, two days before disease onset. For the cases, $63.2 \%$ of their risk period days were rainy - the highest value among all 10,000 realisations, i.e. $p=1 / 10,000$ or 0.0001 . The cases also experienced statistically significant higher mean amounts of rain $(6.5 \mathrm{~mm}$ per day on average during their risk period) than the simulated travellers $(4.5 \mathrm{~mm}$ per day, $p=0.0047)$. One case each from Germany and the UK were in Madeira during one-day cruise ship stops; on both days it rained.

\section{Discussion}

Our investigation supports a temporal association between tourists experiencing rain on Madeira and acquiring dengue fever in late 2012. While the lack of specific control persons may be considered a limitation, the Monte Carlo method is a common statistical technique to assess associations [15]. In our study the lack of specific control persons is compensated by generating hypothetical control individuals based on only few assumptions, e.g. that travel length in controls is similar to the cases regardless of time of arrival. Weighting the analysis with monthly traveller numbers buffers the results against fluctuations caused by other factors (e.g. school holiday periods). The dengue mosquito vector, Aedes aegypti, was first identified in 
Rain exposure, comparison between the set of 42 laboratory-confirmed cases of dengue fever and 9,999 simulated sets of 42 travellers arriving on Madeira, 15 September-21 December 2012 *

$\mathrm{P}=0.0808$

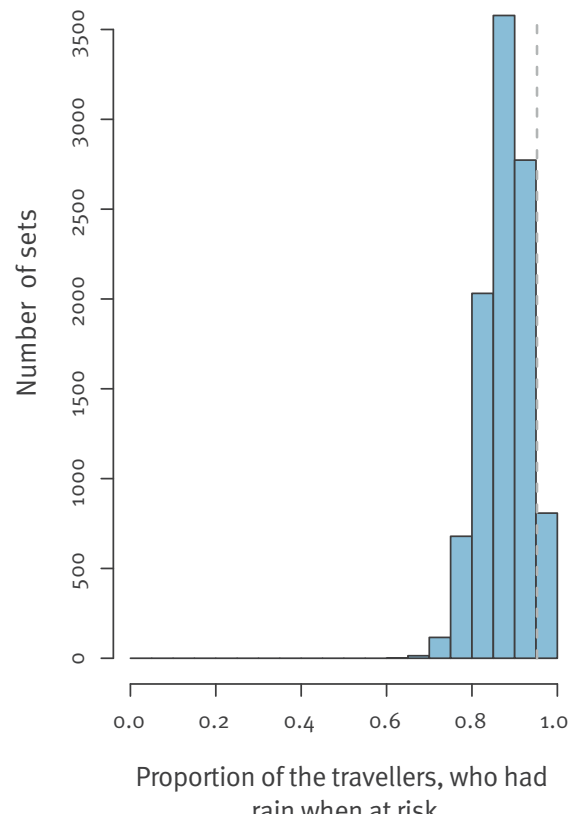

$\mathrm{P}=0.0001$

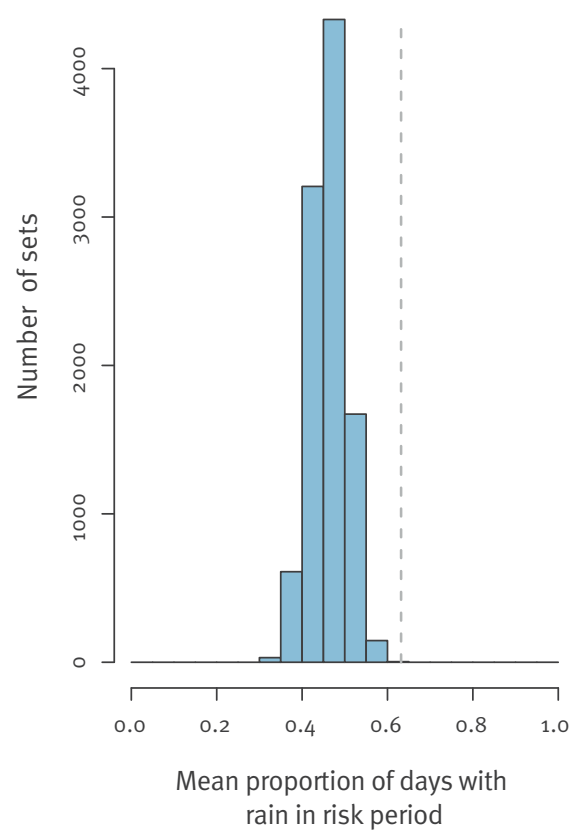

$\mathrm{P}=0.0047$

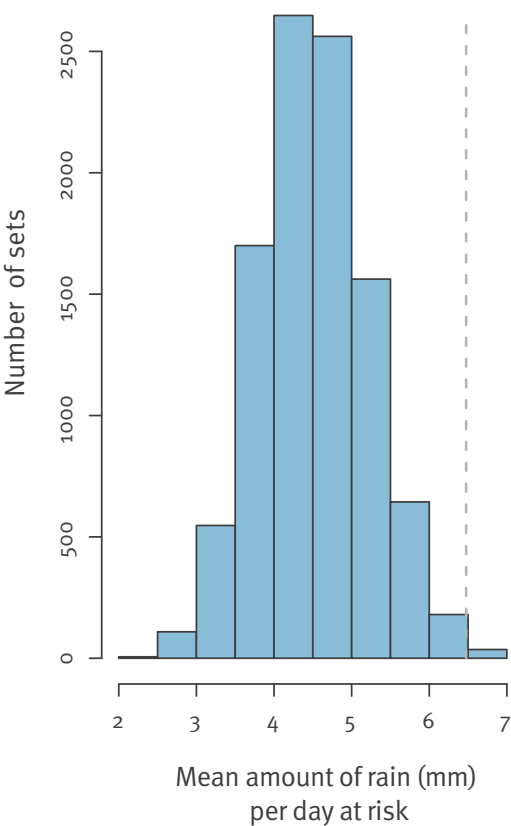

The 42 laboratory-confirmed dengue cases are indicated by a vertical gray dashed line. The 9,999 simulated sets of 42 travellers are shown in the form of blue histograms based on the total 10,000 sets.

Madeira in the mid-200os [16] but no dengue cases were reported in Madeira until October 2012. The lack of recognised cases during the dry and warm summer period before the outbreak and the fact that there were no cases among travellers from Germany and the UK in December, a month with little rain in Madeira, would support the importance of rainfall for dengue virus transmission in Madeira - the trickle of reported cases in travellers from other countries and among Madeirans in December or thereafter is hard to interpret without known onset dates (published data only relies on notification dates). A combination of decreasing temperatures (Figure 1) in December and vector control efforts by the Madeiran authorities [17] may have also contributed to the decrease in cases reported into December [17].

The exact role of rain in dengue virus transmission in Madeira is outside the scope of this paper, but it is important to identify rain as a marker for the temporarily increased risk to those exposed. Our data are in agreement with a tight temporal association - either the infective bites occur on the same days as the rain (possibly before, between or after showers rather than during actual rain), or with a short lag after the rain on following days. Aside from rain-increased mosquito activity another contributing factor could be that travellers may believe they do not need to use mosquito bite avoidance measures as rigorously on rainy days, or it is possible that indoor biting may play a role. Individual risk factors for bites constitute an area that requires further study.

December 2012 and January 2013 so far have been dryer than average ( $4 \mathrm{~mm}$ of rain in both of these months, compared with a median of $113 \mathrm{~mm}$ and $67 \mathrm{~mm}$, for December and January, respectively between 1994 and 2011) [2]. In the coming months both increasing temperatures and rainy periods are to be expected. Until it is clear that the outbreak will not flare up again in 2013, tourists to Madeira (as well as residents) should take precautions as for any area endemic for dengue fever, regardless of the weather: Risk of infection can be reduced by using personal mosquito bite avoidance measures (e.g. cover-up clothing, repellents) during the day, especially around dawn and dusk when Aedes mosquitoes are most active [18]. 


\section{Acknowledgements}

The authors acknowledge the following contributors from the UK: Public Health England (PHE)* Microbiology Services: Rare and Imported Pathogens Laboratory for providing data on laboratory-confirmed dengue cases, and the local PHE* health protection teams for providing supplementary epidemiological data for each case. In Germany, local health departments supplement laboratory notifications with data gained from interviews of patients and their physicians, before referring the case data to the Robert Koch Institute via State Health Departments. Irene Schöneberg checked the German case notifications for completeness.

\section{Conflict of interest}

None declared.

\section{Authors' contributions}

Christina Frank devised the study, contributed analysis and wrote much of the manuscript. Michael Höhle conducted the Monte Carlo test and contributed to writing. Klaus Stark provided advice on methodology and contributed to writing. Joanne Lawrence supplied UK data for the analysis and contributed to the writing and critical review of the manuscript.

\section{${ }^{*}$ Erratum:}

The text and Figure 2 were updated on 05 April 2013.

\section{References}

1. Sousa CA, Clairouin M, Seixas G, Viveiros B, Novo MT, Silva AC, et al. Ongoing outbreak of dengue type 1 in the Autonomous Region of Madeira, Portugal: preliminary report. Euro Surveill. 2012;17(49):pii=20333. Available from: http:// www.eurosurveillance.org/ViewArticle.aspx?Articleld $=20333$ PMid:23231893

2. German National Weather Service (DWD). Monthly rainfall totals at Funchal weather station, Madeira, 1994-2012. Hamburg:DWD. 2013. German.

3. Governo Regional da Madeira - Instituto de Administração da Saúde e Assuntos Sociais. Communicado do Director-Geral da Saúde. Surto de dengue na Ilha da Madeira - situação em 3 de fevereiro de 2013. 2013. [Accessed 15 Feb 2013]. Portuguese. Available from: http://www.dgs.pt/?cn=683368347243AAAAA AAAAAAA

4. European Centre for Disease Prevention and Control (ECDC). Communicable Disease Threats Report (CDTR). Week 7, 10-16 February 2013. Stockholm: ECDC. [Accessed o1 Feb 2013]. Available from: http://ecdc.europa.eu/en/publications/ Publications/communicable-disease-threats-report-16feb-2013.pdf

5. European Centre for Disease Prevention and Control (ECDC). Communicable Disease Threats Report (CDTE). Week 3. 13-19 January 2013. Stockholm: ECDC. [Accessed 01 Feb 2013]. Available from: http://www.ecdc.europa.eu/en/publications/ Publications/communicable-disease-threats-report-19jan-2013.pdf

6. European Centre for Disease Prevention and Control (ECDC) Communicable Disease Threats Report (CDTR). Week 2. 6-12 January 2013. Stockholm: ECDC. [Accessed o1 Feb 2013]. Available from: http://www.ecdc.europa.eu/en/publications/ Publications/Communicable-disease-threats-report-11jan-2013.pdf

7. European Centre for Disease Prevention and Control (ECDC). Communicable Disease Threats Report. Week 1. 30 December 2012-5 January 2013. Stockholm: ECDC. [Accessed 01 Feb 2013]. Available from: http://www.ecdc.europa.eu/en/ publications/Publications/Communicable-diseases-threatsreport-4-jan-2013.pdf

8. Frank C. In Deutschland gemeldete Fälle mit Infektionsort Madeira, Herbst 2012. [Cases of dengue fever infected on Madeira reported in Germany, Fall 2012]. Epid Bull. 2013;2:18 9. German.

9. German National Weather Service (DWD).. Daily amounts of precipitation measured at Funchal weather station, Madeira 1.7.2012-19.1.2013. Hamburg: DWD. 2013. German.

10. Robert Koch Institute (RKI). National database of legally notified infectious diseases (SurvNet) hosted at Robert Koch Institute, Berlin. Berlin:RKI. 2012.

11. UK national dengue database. Data collated nationally by the Travel and Migrant Health Section, Centre for Infectious Disease Surveillance and Control, Public Health England. London: Public Health England; 2013.

12. Heymann DL, editor. Control of Communicable Diseases Manual. 19th ed. Washington D.C.: American Public Health Association; 2008.

13. German National Statistics Office (DESTATIS). Air traffic Series 8, Periodical 6, regarding December 2011, January, JulyNovember 2012. Wiesbaden: DESTATIS; 2012. German.

14. Instituto Nacional De Estatística. Estatísticas do Turismo 2011. Lisbon: Instituto Nacional De Estatística. 2012. Available from: http://www.ine.pt/ngt_server/attachfileu.jsp?look parentBoui $=143016125 \&$ att_display $=n \&$ att_download $=y$

15. Manly BFJ. Randomization, Bootstrap and Monte Carlo Methods in Biology. 2nd Edition ed. Chapman \& Hall/CRC; 1997.

16. Almeida AP, Goncalves YM, Novo MT, Sousa CA, Melim $M$, Gracio Al. Vector monitoring of Aedes aegypti in the Autonomous Region of Madeira, Portugal. Euro Surveill. 2007;12(46):pii=3311. Available from: http://www. eurosurveillance.org/ViewArticle.aspx?Articleld=3311 PMid:18005646

17. Direção-Geral da Saúde. Luta anti vetorial contra Aedes aegypti. Lisbon: Direção-Geral da Saúde. [Accessed 22 Feb 2013]. Portuguese. Available from: http://www.dgs.pt/

18. National Travel Health Network and Centre. Insect and Tick Bite Avoidance. London: National Travel Health Network and Centre. Insect and Tick Bite Avoidance. Updated December 2010. [Accessed 22 Feb 2013]. Available from: http://www.nathnac. org/travel/misc/travellers_mos.htm 